\section{Systematic review of immunomodulatory drugs for the treatment of people with multiple sclerosis: Is there good quality evidence on effectiveness and cost?}

J Bryant, A Clegg, R Milne clinical and cost effectiveness of health technologies and provide guidance to the NHS. At the time of writing, it is considering $\beta$-interferon and glatiramer in the treatment of multiple sclerosis. Excluded from the NICE appraisal are several other disease modifying drugs that may be used in the treatment of this disease. A comprehensive appraisal of disease modifying drugs for the treatment of multiple sclerosis should consider all competing alternatives.

This study is, to the best of our knowledge, the first systematic review of a range of disease modifying drugs for multiple sclerosis. We were commissioned by the NHS Research and Development Health Technology Assessment (HTA) programme to undertake a rapid systematic review to appraise the evidence on the effectiveness and cost of azathioprine, cladribine, cyclophosphamide, intravenous immunoglobulin, methotrexate, and mitoxantrone in reducing relapse rate and in limiting progression among people with multiple sclerosis. This paper summarises and takes forward analyses published in full by the HTA programme. ${ }^{1}$

\section{Methods}

Electronic databases (Medline, PubMed, Embase, Cochrane Systematic Reviews Database, Cochrane Controlled Trials Register, NHS CRD DARE and NHS EED, and the National Research Register) were searched for the period January 1980 to July 1999 (search strategies available on request). Searches were restricted to English language studies. Additional studies were identified through searching bibliographies of related publications and through contact with experts.

We included studies if they were systematic reviews of randomised controlled trials (RCTs), RCTs or cost utility studies that compared an immunomodulatory drug (azathioprine, cladribine, cyclophosphamide, intravenous immunoglobulin, methotrexate, and mitoxantrone) with placebo or another immunomodulatory drug; included people diagnosed with multiple sclerosis who met the criteria for treatment with immunomodulatory drugs; and used patient based outcomes such as relapses, disease progression, and side effects. The list of drugs included in the review was derived from a provisional list from the HTA programme modified after consultation with clinical experts and patient groups on the review advisory panel. Cyclosporine, an immunosuppressant now rarely used, was not included in the review because of its unacceptable adverse effects, 
Table 1 Details of studies of disease modifying drugs in multiple sclerosis

\begin{tabular}{|c|c|c|c|c|}
\hline Intervention & Author and year of study & Study design & Type of $M S$ & Quality score \\
\hline Azathioprine & Yudkin et al $(1991)^{4}$ & Systematic review (7 RCTs) $n=793$ & $\begin{array}{l}\text { RRMS, RPMS, } \\
\text { PMS }\end{array}$ & NHS CRD $4 / 6$ \\
\hline Azathioprine & Milanese et al $(1993)^{5}$ & $\begin{array}{l}\text { RCT (placebo controlled, double blind) } \\
\mathrm{n}=40\end{array}$ & $\begin{array}{l}\text { RRMS, RPMS, } \\
\text { PMS }\end{array}$ & Jadad Score $4 / 5$ \\
\hline Azathioprine & Steck et al $(1990)^{6}$ & RCT (open label) $n=41$ & RPMS & Jadad Score $2 / 5$ \\
\hline Cladribine & Beutler et al $(1996)^{15}$ & RCT (double blind, crossover) $n=48$ & CPMS & Jadad Score 3/5 \\
\hline Cladribine & Romine et al $(1999)^{16}$ & $\begin{array}{l}\mathrm{RCT} \text { (placebo controlled, double blind) } \\
\mathrm{n}=52\end{array}$ & RRMS & Jadad Score $3 / 5$ \\
\hline Cyclophosphamide & Hauser et al $(1983)^{7}$ & RCT (unblinded) $\mathrm{n}=18$ & MS & Jadad Score $1 / 5$ \\
\hline Cyclophosphamide+prednisolone & $\begin{array}{l}\text { Canadian Cooperative MS Study Group } \\
(1991)^{9}\end{array}$ & RCT $n=168$ & RPMS, CPMS & Jadad Score $2 / 5$ \\
\hline Cyclophosphamide & Killian et al $(1988)^{8}$ & RCT (double blind, crossover) $n=14$ & RRMS & Jadad Score $4 / 5$ \\
\hline Cyclophosphamide & Likosky et al $(1991)^{10}$ & RCT (single blind) $\mathrm{n}=41$ & CPMS & Jadad Score $2 / 5$ \\
\hline Cyclophosphamide & Weiner at al $(1993)^{11}$ & RCT (single blind) $n=256$ & PMS & Jadad Score $1 / 5$ \\
\hline Intravenous immunoglobulin & Achiron et al $(1998)^{12}$ & $\begin{array}{l}\text { RCT (placebo controlled, double blind) } \\
\mathrm{n}=40\end{array}$ & RRMS & Jadad Score $5 / 5$ \\
\hline Intravenous immunoglobulin & Sorensen et al $(1997)^{13}$ & RCT (double blind, crossover) $n=25$ & RRMS, RPMS & Jadad Score 3/5 \\
\hline Intravenous immunoglobulin & Fazekas et al $(1997)^{14}$ & $\begin{array}{l}\text { RCT (placebo controlled, double blind) } \\
\mathrm{n}=148\end{array}$ & RRMS & Jadad Score $5 / 5$ \\
\hline Methotrexate & Currier et al $(1993)^{20}$ & RCT (double blind) $\mathrm{n}=44$ & All MS & Jadad Score $2 / 5$ \\
\hline Methotrexate & Goodkin et al $(1995)^{19}$ & RCT (double blind) $\mathrm{n}=60$ & CPMS & Jadad Score $4 / 5$ \\
\hline Mitoxantrone & Millefiorini et al $(1997)^{17}$ & $\begin{array}{l}\text { RCT (placebo controlled, double blind) } \\
\mathrm{n}=51\end{array}$ & RRMS & Jadad Score $4 / 5$ \\
\hline Mitoxantrone & Edan et al $(1997)^{18}$ & RCT (double blind) $n=42$ & RRMS, SPMS & Jadad Score 3/5 \\
\hline
\end{tabular}

RCT $=$ Randomised controlled trial. CPMS=chronic progressive MS, RPMS=relapsing progressive MS, RRMS=relapsing-remitting $M S$, PMS=progressive MS, SPMS=secondary progressive MS.

notably nephrotoxicity and hypertension, which outweigh any modest clinical benefit and affect compliance. Outcome measures, either relapses or disease progression, or both, are the primary and secondary outcomes as reported in the literature, regardless of whether strictly appropriate for the type of multiple sclerosis under consideration. Side effects are listed as reported in the studies.

Included studies were assessed using standard critical appraisal criteria, with the quality of systematic reviews scored using criteria developed by NHS CRD ${ }^{2}$ and RCTs using the scale developed by Jadad et al. ${ }^{3}$ Decisions on inclusion criteria, quality criteria, and data extraction were made by one reviewer. These decisions were checked by a second reviewer, with any disagreements resolved through discussion.

Studies were combined through narrative synthesis, as differences in the type and definition of outcomes, patient characteristics (type of disease pattern, duration of disease, and duration of follow up) and drug dose and administration prevented any meta-analysis. Numbers needed to treat (NNTs) with 95\% confidence intervals (95\% CIs) were calculated where figures were presented in an appropriate form. For relapse outcomes, we calculated NNTs to prevent relapse at 1 year and at the longest follow up period; for disease progression, we calculated NNTs to prevent worsening by one EDSS point at 1 year and at longest follow up period available. The NNTs were included even when the effectiveness results did not reach conventional significance.

Cost data were presented as annual drug costs/patient, calculated using individual drug costs (British National Formulary 1999 and Southampton Drug Information Unit) and dosages stated in trials, British National Formulary, or from expert opinion.

\section{Results}

QUANTITY AND QUALITY OF STUDIES

Seventeen studies, either systematic reviews or RCTs, met the inclusion criteria. No studies of cost utility were found. Table 1 presents study details and quality scores for the different immunomodulatory drugs. The quantity and quality of studies varied between the different immunomodulatory drugs. Evidence on the effectiveness of azathioprine came from a good quality systematic review ${ }^{4}$ and two subsequent RCTs: one good quality placebo controlled double blind trial ${ }^{5}$ and one poor open label RCT. $^{6}$ Of the five RCTs assessing cyclophosphamide, ${ }^{7-11}$ only one was a good quality double blind crossover RCT. $^{8}$ The remaining four were of poor quality, either lacking descriptions of randomisation or details of withdrawals, and none were double blinded. Blinding is often difficult due to the inevitable adverse effects, such as alopecia. By contrast, the three $\mathrm{RCTs}^{12-14}$ examining intravenous immunoglobulin were of good or fairly good quality. For both cladribine ${ }^{1516}$ and mitoxantrone ${ }^{1718}$ there were two fairly good RCTs, and for methotrexate there was one good quality $^{19}$ and one poor quality RCT. ${ }^{20}$

EVIDENCE FOR THE EFFECTIVENESS ON RELAPSE RATE (TABLE 2)

Azathioprine

Two studies, the systematic review (score $4 / 6)^{4}$ and the RCT (score 4/5), ${ }^{5}$ showed significantly lower relapse rates among patients with relapsing-remitting, primary progressive, or secondary relapsing progressive multiple sclerosis receiving azathioprine than patients receiving placebo, after 3 years of treatment. Odds of freedom from relapse at 3 years and relative risk of relapse were reported. The NNTs to prevent relapse at 1 year were calculated as 10 and 7 (95\%CI 3-infinity) respectively. The third study (score $2 / 5)^{6}$ did not report on relapse rate.

\section{Cladribine}

One study (score $3 / 5)^{16}$ considered patients with relapsing-remitting disease and reported the effects of cladribine on relapse rate. Comparison of the combined measure of 
frequency and severity of relapses using Mantel's extension of the Mantel-Haenzel procedure showed a reduction in the cladribine group compared with placebo in patients with relapsing-remitting disease, but there were no significant differences between treatment groups in relapse rate. It was not possible to calculate NNTs from the data supplied.

\section{Cyclophosphamide}

The one study of cyclophosphamide scoring $4 / 5^{8}$ reported on the mean number of relapses in patients with relapsing-remitting disease. The cyclophosphamide group showed a decrease in the mean number of relapses compared with placebo but results did not achieve significance. The NNT was calculated from the data as 4 (95\% CI 2-infinity).

\section{Intravenous immunoglobulin}

In the two studies of intravenous immunoglobulin scoring $5 / 5^{12} 14$ in patients with relapsing-remitting multiple sclerosis, relapse rate (reported as mean annual relapse rate and yearly exacerbation rate) was significantly reduced in the intravenous immunoglobulin group compared with placebo. The relative risk of relapse was estimated from these studies at 0.79 and 0.72 , suggesting that there may be some benefit of treatment with intravenous immunoglobulin in relapsing-remitting multiple sclerosis. The NNTs were calculated as 3 $(95 \%$ CI $2-10)$ at 1 year and $6(95 \%$ CI $4-61)$ at 2 years respectively. The third trial (score $3 / 5)^{13}$ reported an increased number of patients with no relapses in the intravenous group, with NNT calculated as 5 (95\% CI 3-infinity).
Methotrexate

One study of methotrexate (score 2/5) 20 reported the number of people experiencing exacerbations, in a small subset of patients with relapsing-remitting disease, and showed no overall difference in outcome between treatment groups when considering all types of multiple sclerosis. The NNT was calculated as 23 (95\% CI 4-infinity) at 18 months.

\section{Mitoxantrone}

Both trials of mitoxantrone reported significant reductions in relapses and exacerbations among patients receiving mitoxantrone rather than placebo or other treatment. In one study (score $4 / 5)^{17}$ patients with relapsing-remitting disease receiving mitoxantrone had fewer relapses than patients on placebo during 2 years of treatment. The other study (score $3 / 5)^{18}$ found significantly reduced mean annual relapse rates/patient for mitoxantrone and methylprednisolone over 6 months of treatment. The NNTs were calculated as $3(95 \% \mathrm{CI}$ $2-6)$ at 1 year and $3(95 \% \mathrm{CI} 2-37)$ at 6 months respectively.

\section{EVIDENCE FOR DELAY IN DISEASE PROGRESSION}

(TABLE 3)

Azathioprine

The systematic review ${ }^{4}$ and RCT (score $\left.4 / 5\right)^{5}$ examined azathioprine against placebo for relapsing-remitting, relapsing-progressive and progressive multiple sclerosis, and results suggested that there was slower progression in disease severity among patients receiving azathioprine compared with controls. Although not significant, these differences increased over time, up to 3 years. The NNT to prevent

Table 2 Summary of evidence of effectiveness on relapse rate of disease modifying drugs in multiple sclerosis

\begin{tabular}{|c|c|c|c|}
\hline \multirow[b]{2}{*}{ Study } & \multirow[b]{2}{*}{ Effectiveness on relapse rate } & \multicolumn{2}{|l|}{ NNT to prevent relapse } \\
\hline & & $\begin{array}{l}\text { At } 1 \text { year unless otherwise stated } \\
(95 \% \mathrm{CI})\end{array}$ & $\begin{array}{l}\text { At longest follow up period } \\
(95 \% \mathrm{CI})\end{array}$ \\
\hline \multicolumn{4}{|l|}{ Azathioprine } \\
\hline Yudkin et al $(1991)^{4}$ & $\begin{array}{l}\text { Odds of freedom from relapse at } 3 \text { years for } \\
\text { azathioprine patients } 1.97(95 \% \text { CI } 1.27-3.04)\end{array}$ & $10^{\star}$ & $14^{\star}$ at 3 years \\
\hline Milanese et al (1993) $)^{5}$ & $\begin{array}{l}\text { Relative risk of relapse over } 3 \text { years for control } \\
\text { patients } 1.6(95 \% \text { CI } 1.07-2.49)\end{array}$ & 7 (3 to infinity) & $3(2$ to 12$)$ at 3 years \\
\hline Steck et al $(1990)^{6}$ & $\mathrm{~N} / \mathrm{A}$ & $\mathrm{N} / \mathrm{A}$ & N/A \\
\hline \multicolumn{4}{|l|}{ Cladribine } \\
\hline Beutler et al $(1996)^{15}$ & N/A & N/A & $\mathrm{N} / \mathrm{A}$ \\
\hline Romine et al $(1999)^{16}$ & $\begin{array}{l}\text { Non-significant effects of cladribine on relapse } \\
\text { rate }\end{array}$ & No patient data & N/A \\
\hline \multicolumn{4}{|l|}{ Cyclophosphamide (CYC) } \\
\hline Hauser et al $(1983)^{7}$ & N/A & N/A & N/A \\
\hline $\begin{array}{l}\text { Canadian Cooperative MS Study Group } \\
(1991)^{9}\end{array}$ & $\mathrm{~N} / \mathrm{A}$ & N/A & N/A \\
\hline Killian et al $(1988)^{8}$ & Non-significant effect of CYC on relapse rate & 4 (2 to infinity) & N/A \\
\hline Likosky et al $(1991)^{10}$ & N/A & N/A & N/A \\
\hline Weiner at al $(1993)^{11}$ & $\mathrm{~N} / \mathrm{A}$ & N/A & N/A \\
\hline \multicolumn{4}{|l|}{ Intravenous immunoglobulin (IVIg) } \\
\hline Achiron et al (1998) & $\begin{array}{l}\text { Yearly relapse rate: IVIg } 0.59 v \text { placebo } 1.61 \\
(p=0.006)\end{array}$ & $3(2$ to 10$)$ & $3(2$ to 7$)$ at 2 years \\
\hline Sorensen et al $(1997)^{13}$ & $\begin{array}{l}\text { Patients with no relapses: IVIg } 11 v \text { placebo } 6 \\
(\mathrm{p}=0.05)\end{array}$ & 5 (3 to infinity) at 6 months & N/A \\
\hline Fazekas et al $(1997)^{14}$ & $\begin{array}{l}\text { Mean annual relapse rate: IVIg } 0.52 v \text { placebo } \\
1.26(\mathrm{p}=0.0037)\end{array}$ & $\mathrm{N} / \mathrm{A}$ & $6(4$ to 61$)$ at 2 years \\
\hline \multicolumn{4}{|l|}{ Methotrexate } \\
\hline Currier et al $(1993)^{20}$ & Non-significant effect on relapse rate & $\mathrm{N} / \mathrm{A}$ & 23 (4 to infinity) at 18 months \\
\hline Goodkin et al (1995) ${ }^{19}$ & N/A & $\mathrm{N} / \mathrm{A}$ & N/A \\
\hline \multicolumn{4}{|l|}{ Mitoxantrone (MIT) } \\
\hline Millefiorini et al $(1997)^{17}$ & $\begin{array}{l}\text { Difference in mean: } 1.73 \text { fewer relapses with } \\
\text { MIT than placebo } p=0.0002 \text { over } 2 \text { years }\end{array}$ & $3(2$ to 6$)$ & 3 (2 to 7$)$ at 2 years \\
\hline Edan et al $(1997)^{18}$ & $\begin{array}{l}\text { Annual relapse rate: methylprednisolone } \\
+ \text { MIT } 0.7 v \text { methylprednisolone } 3.0(\mathrm{p}<0.01)\end{array}$ & 3 (2 to 37$)$ at 6 months & N/A \\
\hline
\end{tabular}

${ }^{\star}$ Calculated from data in systematic review, not from original trial data, using method described by Sackett. ${ }^{23}$ 
Table 3 Summary of evidence of effectiveness on disease progression of disease modifying drugs in MS

\begin{tabular}{|c|c|c|c|}
\hline \multirow[b]{2}{*}{ Study } & \multirow[b]{2}{*}{ Effectiveness on disease progression } & \multicolumn{2}{|l|}{ NNT to prevent worsening on EDSS } \\
\hline & & $\begin{array}{l}\text { At } 1 \text { year unless otherwise stated } \\
(95 \% \mathrm{CI})\end{array}$ & $\begin{array}{l}\text { At longest follow up period } \\
(95 \% \mathrm{CI})\end{array}$ \\
\hline \multicolumn{4}{|l|}{ Azathioprine: } \\
\hline Yudkin et al $(1991)^{4}$ & Non-significant delays in progression $v$ placebo & No patient data & N/A \\
\hline Milanese et al $(1993)^{5}$ & Non-significant delays in progression $v$ placebo & -66 (-infinity to -3$)$ & $3(2$ to 6$)$ at 3 years \\
\hline Steck et al $(1990)^{6}$ & Non-significant delays in progression & No patient data & N/A \\
\hline \multicolumn{4}{|l|}{ Cladribine: } \\
\hline Beutler et al $(1996)^{15}$ & $\begin{array}{l}\text { ANOVA based on } 2 \text { year crossover: EDSS } \\
F=10.19(\mathrm{p}=0.0026) \text { and SRS } F=23.46 \\
(\mathrm{p}<0.0001)\end{array}$ & $4(3$ to 19$)$ & N/A \\
\hline Romine et al (1999) ${ }^{16}$ & $\begin{array}{l}\text { No significant differences between treatment } \\
\text { groups }\end{array}$ & No patient data & N/A \\
\hline \multicolumn{4}{|l|}{ Cyclophosphamide: } \\
\hline Hauser et al $(1983)^{7}$ & $\begin{array}{l}\text { Change in EDSS at } 1 \text { year: CYC+ACTH }-0.5 \\
v \text { ACTH alone }+0.7(\mathrm{p}<0.01)\end{array}$ & $2(2$ to 4$)$ & N/A \\
\hline $\begin{array}{l}\text { Canadian Cooperative MS Study } \\
\text { Group }(1991)^{9}(+ \text { prednisolone })\end{array}$ & $\begin{array}{l}\text { No significant differences in EDSS between } \\
\text { treatment groups }\end{array}$ & 11 (5 to infinity) & $\begin{array}{l}-7 \text { (minus infinity to }-3) \text { at } 3 \\
\text { years }\end{array}$ \\
\hline Killian et al $(1988)^{8}$ & No significant differences in EDSS & No patient data & N/A \\
\hline Likosky et al $(1991)^{10}$ & No significant differences in EDSS & -15 (minus infinity to -2 ) & $\begin{array}{l}-10(\text { minus infinity to }-2) \text { at } 2 \\
\text { years }\end{array}$ \\
\hline Weiner at al (1993) ${ }^{11}$ & $\begin{array}{l}\text { Results expressed as } 38 \% \text { stable/improved with } \\
\text { booster CYC vs } 24 \% \text { no boosters }(\mathrm{p}=0.04)\end{array}$ & 9 (5 to infinity) & 21 (7 to infinity) at 3 years \\
\hline \multicolumn{4}{|l|}{ Intravenous immunoglobulin: } \\
\hline Achiron et al $(1998)^{12}$ & $\begin{array}{l}\text { No significant differences between treatment } \\
\text { groups }\end{array}$ & No patient data & N/A \\
\hline Sorensen et al $(1997)^{13}$ & No significant differences & No patient data & N/A \\
\hline Fazekas et al $(1997)^{14}$ & $\begin{array}{l}\text { Mean change in EDSS at } 2 \text { years: IVIg }-0.23 \text { vs } \\
\text { placebo } 0.12(p=0.008)\end{array}$ & N/A & 14 (5 to infinity) at 2 years \\
\hline \multicolumn{4}{|l|}{ Methotrexate: } \\
\hline Currier et al $(1993)^{20}$ & No significant differences & N/A & $\begin{array}{l}\text { ( } 4 \text { to infinity) at } 1.5 \text { years results } \\
\text { identical }\end{array}$ \\
\hline Goodkin et al (1995) $)^{19}$ & $\begin{array}{l}\text { Composite measure of treatment failure: } \mathrm{MTX} \\
51.6 \% v \text { placebo } 82.8 \%(\mathrm{p}=0.011)\end{array}$ & $\begin{array}{l}3 \text { ( } 2 \text { to } 7) \text { composite score } 5 \\
\text { ( } 3 \text { to } 44) \text { EDSS }\end{array}$ & $\begin{array}{l}3 \text { ( } 2 \text { to } 6) \text { composite score, } 7 \text { ( } 3 \\
\text { to infinity) EDSS at } 2 \text { years }\end{array}$ \\
\hline \multicolumn{4}{|l|}{ Mitoxantrone: } \\
\hline Millefiorini et al $(1997)^{17}$ & $\begin{array}{l}\text { Difference in proportion of patients progressed } \\
1 \text { EDSS at } 2 \text { years: additional } 18 \% \text { on placebo } \\
(\mathrm{p}=0.02)\end{array}$ & 6 (3 to infinity) & $4(2$ to 13$)$ at 2 years \\
\hline Edan et al $(1997)^{18}$ & $\begin{array}{l}\text { Mean change in EDSS at } 6 \text { months: } \\
\text { methylprednisolone }+ \text { MIT }-1.1 v \\
\text { methylprednisolone }-0.1(\mathrm{p}<0.05)\end{array}$ & 5 (3 to 85$)$ at 6 months & N/A \\
\hline
\end{tabular}

EDSS=Expanded disability status scale.

worsening on EDSS could not be calculated from the systematic review as data were not available. Therefore the NNT was calculated from the one study that reported this outcome as $-66(95 \% \mathrm{CI}-$ infinity to -3$)$ at 1 year. ${ }^{5}$ This represents a small and non-significant worsening in outcome on azathiprine: a result in the opposite direction to the result in column 2 of table 3, which was based on a non-significant reduction in the mean changes in EDSS from baseline compared with placebo. Patients with relapsing-progressive multiple sclerosis treated with cyclosporine had a delay in progression compared with azathioprine although results were not significantly different. ${ }^{6}$ No patient data were reported for calculation of NNT.

\section{Cladribine}

One crossover study (score $3 / 5)^{15}$ reported highly significant treatment effects of cladribine on disease progression in chronic progressive multiple sclerosis at both 1 year and 2 years compared with placebo. The NNT was calculated from the data as $4(95 \%$ CI 3-19). The other study (score 3/5), ${ }^{16}$ showed no delay in progression, but this can be expected as only patients with relapsing-remitting multiple sclerosis were considered and disability accrues more slowly in such patients and therefore progression may not be a good outcome measure for this group. No patient data were reported to allow calculation of NNT.
Cyclophosphamide

One study (score $1 / 5)^{7}$ in progressive multiple sclerosis suggested that cyclophosphamide combined with adrenocorticotropic hormone may be of some benefit, with NNT to prevent worsening on EDSS at 1 year calculated from the data as $2(95 \%$ CI $2-4)$. Another trial (score $1 / 5)^{11}$ suggested that boosters of cyclophosphamide may slow progression, with NNT calculated as 9 (95\% CI 5-infinity). The other studies (scores $4 / 5,2 / 5,2 / 5)^{8-10}$ did not confirm a delay in progression; this was to be expected in one trial ${ }^{8}$ which only included patients with relapsing-remitting multiple sclerosis.

\section{Intravenous immunoglobulin}

One trial (score $5 / 5)^{14}$ in patients with relapsing-remitting disease, suggested that there was some improvement in clinical disability in the intravenous immunoglobulin group compared with further deterioration in the placebo group after 2 years of treatment. The NNT was calculated as $14 \quad(95 \% \mathrm{CI}$ 5 -infinity) at 2 years. The other two studies (score $5 / 5,3 / 5)^{12} 13$ did not produce significant results, although this was not unexpected in one study ${ }^{12}$ as only patients with relapsingremitting multiple sclerosis were included. There were no patient data from which to calculate NNTs.

\section{Methotrexate}

Results from the study of methotrexate in chronic progressive multiple sclerosis (score 
Table 4 Annual drug costs/patient

\begin{tabular}{ll}
\hline Drug & Annual drug cost \\
\hline Azathioprine & $£ 300$ (non-proprietary) \\
Cladribine & $£ 6000$ to $£ 9000$ \\
Cyclophosphamide & Up to about $£ 60$ \\
Intravenous immunoglobulin & $£ 1600$ to $£ 10200$ \\
Methotrexate & $£ 60$ (non-proprietary) \\
Mitoxantrone & $£ 2000$
\end{tabular}

$4 / 5)^{19}$ suggested a treatment effect when using a composite outcome measure of treatment failure only. The NNT was calculated as 3 (95\% CI 2-7) for the composite score and 5 (95\%CI 3-44) for EDSS alone. The other study (score $2 / 5)^{20}$ showed no overall difference in outcome between the treatment groups when considering all types of multiple sclerosis.

\section{Mitoxantrone}

Both trials of mitoxantrone reported significant delays in disability progression. The trial with patients with relapsing-remitting multiple sclerosis (score $4 / 5)^{17}$ showed that fewer patients treated with mitoxantrone progressed one point on the EDSS compared with patients on placebo. The NNT was calculated as $6(95 \% \mathrm{CI}$ 3-infinity). The other study (score $3 / 5)^{18}$ considered both patients with relapsingremitting multiple sclerosis and those with secondary progressive disease treated with mitoxantrone plus methylprednisolone, and showed a greater improvement in mean EDSS compared with patients receiving methylprednisolone alone. The NNT was calculated as 5 (95\% CI 3-85) at 6 months.

SIDE EFFECTS

A range of adverse effects was reported for these six immunomodulatory drugs for multiple sclerosis, some of which were transient and mild, others more severe. Azathioprine may cause gastrointestinal side effects, with up to $11 \%$ of patients reported in one study ${ }^{5}$ having intolerable vomiting, which may affect compliance. A wide range of side effects was reported in all studies of cyclophosphamide, most commonly alopecia, vomiting, nausea, amenorrhoea, and urticaria and this may not be well tolerated. For intravenous immunoglobulin, mild headache may occur transiently within the first 24 hours of infusion. Mitoxantrone is generally well tolerated but may cause nausea, amenorrhoea, and alopecia. Methotrexate is reported as being tolerated reasonably well, but side effects include nausea and alopecia. Cladribine is generally well tolerated.

COSTS OF MULTIPLE SCLEROSIS DRUGS

Annual drug costs (table 4) ranged widely from $£ 60 /$ year for treatment with methotrexate to $£ 10200$ for intravenous immunoglobulin. These costs do not include administration of the drug, any other drugs prescribed with an immunomodulatory drug, or any costs associated with monitoring. It is not possible to quantify potential savings to the health care and welfare sectors due to reduced admission to hospital due to relapse, reduced disability, and maintenance of employment by the patient and carer.

\section{Discussion and conclusions}

Our rapid and systematic review summarises the quantity and quality of the evidence on six immunomodulatory drugs for the treatment of people with multiple sclerosis. We found that the 17 studies identified for inclusion in the review were of variable quality. Although there were good quality studies, all too often these were of small size and/or short duration. As a consequence, it is not known how long any of the potential benefits of these drugs may last and whether if maintained they accumulate over time. In those studies affected by methodological limitations, the most important were inadequate blinding to treatment allocation, poor description of withdrawals and drop outs, and incomplete reporting of results and contextual information. Although some limitations are difficult to avoid, they make interpretation of evidence difficult and provide the opportunity for bias. In addition, comparisons were restricted by the lack of consistency in treatment regimes, patient groups, and outcome measures used. Change in terminology over time has also made interpretation difficult, with the term chronic progressive multiple sclerosis now commonly divided into primary and secondary progressive. Also, it should be noted that the widely recognised quality assessment method used here may reflect how well a study has been reported rather than the actual methodological quality of the study. ${ }^{21}$

Trials did not always report the most appropriate outcome measure for the patient group recruited to the study - for example, disability progression is reported for patients with relapsing-remitting multiple sclerosis although disease progression may accrue more slowly in this group. However, severity of relapses may be measured by change in disability. Some studies recruited patients with relapsing and progressive forms of disease but did not distinguish patient groups in results. Side effects are not well measured or reported in the studies, but need to be considered in terms of individual patients and general compliance.

Although these drugs have been shown to have some beneficial effect on relapse rates or disease progression in different groups of patients, these are limited and their benefit may be lessened by the side effects of treatment. Azathioprine may reduce the relapse rate in patients with relapsing-remitting, relapsingprogressive, and progressive multiple sclerosis, but unpleasant side effects are common and some patients are unable to tolerate them. Cladribine may be effective in delaying disease progression in progressive multiple sclerosis, but seems to have little benefit in relapsingremitting multiple sclerosis. Cyclophosphamide, when combined with adrenocorticotropic hormone or when used as a booster, may slow progression but is associated with a wide range of side effects. Intravenous immunoglobulin seems to reduce relapse rates among patients with relapsing-remitting multiple sclerosis, but also has a wide range of side effects. Methotrexate may have a beneficial effect on patients with progressive disease, although this is only evident through a 
composite measure of treatment failure. Mitoxantrone may benefit patients with relapsingremitting multiple sclerosis through delayed progression and reduce relapse rates, although side effects are reported.

The main strength of this rapid systematic review is that it is comprehensive for a wide range of disease modifying drugs for multiple sclerosis, and methodologically sound, applying consistent methods of critical appraisal and presentation. The review was guided by the principles for undertaking a systematic review ${ }^{2}$ and followed a research protocol which was commented on by an advisory group. The advisory group, comprising representation from a patient group, academic and clinical neurology, and health authority advisors, informed the review from its initiation through to completion, offering invaluable advice at all stages.

The systematic review focused on patient based outcome measures, such as disease progression, relapses, and side effects. Studies using non-patient outcomes only, specifically the use of MRI, were excluded from the review. The omission of MRI may be regarded as weakening the strength of the review. However, uncertainty remains about the interpretation and clinical significance of MRI results in multiple sclerosis. ${ }^{22}$ As such, it was decided to exclude results of MRI or other non-patient outcomes from the outset and this restriction is unlikely to have introduced any bias into the review.

Another potential opportunity for bias was the lack of unpublished studies and the restriction of the research to English language studies only. Although companies manufacturing the drugs and experts in the topic area were contacted, no additional unpublished studies were obtained.

Some of the drugs considered in this review are expensive. That of course does not mean they should not be prescribed: what will matter to those who formulate clinical policy, whether at the hospital or national level, is the balance of benefits, harms, acceptability to patients, and costs. This will require a full economic evaluation, probably in the form of a costeffectiveness or cost-utility study. A recent systematic review of the cost-utility of $\beta$-interferon in multiple sclerosis found four studies but concluded that none of them provided a full comparison of relevant healthcare strategies. ${ }^{24}$ Further economic evaluations of a wider range of possible interventions, such as improved supportive care, were needed so that scarce resources could be used effectively.

Access to good quality evidence on the clinical and cost effectiveness of disease modifying drugs for multiple sclerosis is restricted by concerns over the methodological rigour of studies and the variations between treatment regimes, patients groups, and outcome measures. Current evidence suggests that disease modifying drugs provide some limited benefit to people with multiple sclerosis, but with a wide range of side effects. Further long term RCTs using clinically significant outcome measures for different groups of people with multiple sclerosis, alongside well conducted comparative economic evaluations, are required.

This review was funded by the NHS R and D Health Technology Assessment Programmes. The views and opinions expressed
therein are those of the authors and do not necessarily reflect therein are those of the auth
those of the NHS Executives.

1 Clegg A, Bryant J, Milne R. Disease modifying drugs for multiple sclerosis: a rapid and systematic review. Health Technol Assess 2000;4.

2 NHS Centre for Reviews and Dissemination. Undertaking systematic reviews of research on effectiveness: CRD Guidelines for those carrying out or commissioning reviews. York: Report 4.

3 Jadad AR, Moore A, Carroll D, et al. Assessing the quality of reports of randomised clinical trials: is blinding necessary? Control Clin Trials 1996;17:1-12.

4 Yudkin PL, Ellison GW, Ghezzi A, et al. Overview of azathioprine treatment in multiple sclerosis [comments]. Lancet 1991;338:1051-5.

5 Milanese C, La Mantia L, Salmaggi A, et al. A double blind study on azathioprine efficacy in multiple sclerosis: final report. F Neurol 1993;240:295-8.

6 Steck AJ, Regli F, Ochsner F, et al. Cyclosporine versus azathioprine in the treatment of multiple sclerosis: 12 month clinical and immunological evaluation. Eur Neurol 1990;30: $224-8$.

7 Hauser SL, Dawson DM, Lehrich JR, et al. Intensive immunosuppression in progressive multiple sclerosis. A randomized, three-arm study of high-dose intravenous cycloomized, three-arm study of high-dose intravenous cyclo-
phosphamide, plasma exchange, and ACTH. N Engl f Med phosphamide, plas

1983;308:173-80.
8 Killian JM, Bressler RB, Armstrong RM, et al. Controlled pilot trial of monthly intravenous cyclophosphamide in multiple sclerosis. Arch Neurol 1988;45:27-30.

9 The Canadian cooperative trial of cyclophosphamide and plasma exchange in progressive multiple sclerosis. The Canadian Cooperative Multiple Sclerosis Study Group [comments]. Lancet 1991;337:441-6.

10 Likosky WH, Fireman B, Elmore R, et al. Intense immunosuppression in chronic progressive multiple sclerosis: the Kaiser study. F Neurol Neurosurg Psychiatry 1991;54:105560 .

11 Weiner HL, Mackin GA, Orav EJ, et al. Intermittent cyclophosphamide pulse therapy in progressive multiple sclerosis: final report of the Northeast Cooperative Multiple Sclerosis Treatment Group [comments]. Neurology 1993;43:910-8.

12 Achiron A, Gabbay U, Gilad R, et al. Intravenous immunoglobulin treatment in multiple sclerosis. Effect on immunoglobulin treatment in multiple

13 Sorensen PS, Wanscher B, Jensen CV, et al. Intravenous immunoglobulin $\mathrm{G}$ reduces MRI activity in relapsing multiple sclerosis. Neurology 1998;50:1273-81.

14 Fazekas F, Deisenhammer F, Strasser Fuchs S, et al. Randomised placebo-controlled trial of monthly intravenous immunoglobulin therapy in relapsing-remitting multiple sclerosis. Austrian Immunoglobulin in Multiple Sclerosis Study Group [comments]. Lancet 1997;349:58993

15 Beutler E, Sipe JC, Romine JS, et al. The treatment of chronic progressive multiple sclerosis with cladribine. Proc Natl Acad Sci USA 1996;93:1716-20.

16 Romine JS, Sipe JC, Koziol JA, et al. A double-blind, placebo-controlled, randomized trial of cladribine in relapsing-remitting multiple sclerosis. Proc Assoc Am Physicians 1999;111:35-44.

17 Millefiorini E, Gasperini C, Pozzilli C, et al. Randomized placebo-controlled trial of mitoxantrone in relapsingremitting multiple sclerosis: 24 month clinical and MRI outcome. 7 Neurol 1997;244:153-9.

18 Edan G, Miller D, Clanet M, et al. Therapeutic effect of mitoxantrone combined with methylprednisolone in multiple sclerosis: a randomised multicentre study of active disease using MRI and clinical criteria [comments]. I Neurol Neurosurg Psychiatry 1997;62:112-8.

19 Goodkin DE, Rudick RA, VanderBrug Medendorp S, et al. Low-dose $(7.5 \mathrm{mg})$ oral methotrexate reduces the rate of progression in chronic progressive multiple sclerosis [comments]. Ann Neurol 1995;37:30-40.

20 Currier RD, Haerer AF, Meydrech EF. Low dose oral methotrexate treatment of multiple sclerosis: a pilot study [published erratum appears in 7 Neurol Neurosurg Psychiatry ished erratum appears in Feurol Neurosurg Psychiatry 1217-8.

21 Juni P, Witschi A, Bloch R, et al. The hazards of scoring the quality of clinical trials for meta-analysis. $¥ A M A$ 1999;282: quality of

22 Kappos L, Moeri D, Raude EW. Predictive value of gadolinium-enhanced magnetic resonance imaging for relapse rate and changes in disability or impairment in multiple sclerosis; a meta-analysis. Lancet 1999;353:964-9.

23 Sackett DL, Deeks JJ, Altman DG. Down with odds ratios! Evidence Based Medicine 1996;1:164-6.

24 Bryant J, Clegg A, Milne R. Cost utility of drugs for multiple sclerosis: systematic review places study in context. BMF 2000;320:1474. 